\title{
Oral Transmission of Sexually Transmissable Infections: A Narrative Review
}

\author{
Transmissão Oral de Infeções Sexualmente \\ Transmissíveis: Uma Revisão Narrativa
}

\author{
Catarina QUEIRÓS $\square^{1}$, João Borges da COSTA ${ }^{1,2,3}$ \\ Acta Med Port 2019 Dec;32(12):776-781 - https://doi.org/10.20344/amp.12191
}

\begin{abstract}
Over the last few decades, behavioral changes in sexual practices have made oral transmission of traditional sexually transmissible infections increasingly recognized. Patients harboring a sexually transmissible infection may first present lesions on the oral cavity, as these may be visible and interfere with basic functions such as speech or swallowing. Moreover, the oral cavity may function as a reservoir for future spread of these infections. In order to successfully control this problem, a greater focus on oral sex should be persued, along with promotion of the use of condom and education on safe oral sex practices. Furthermore, examination of the oral cavity should is essential when evaluating any patient suspected of harboring a sexually transmissible infection. In this article, oral transmission of several viral and bacterial infections is reviewed, including human papillomavirus infection, genital herpes, syphilis and gonorrhea, among others.
\end{abstract}

Keywords: Mouth Diseases; Sexual Behavior; Sexually Transmitted Diseases/transmission

\section{RESUMO}

Com as alterações comportamentais nas práticas sexuais verificadas nas últimas décadas, a transmissão oral de infeções sexualmente transmissíveis tem vindo a ser progressivamente mais reconhecida. As lesões na cavidade oral podem ser visíveis ou interferir com funções básicas como a fala ou deglutição, sendo por isso o motivo de apresentação de muitos destes doentes. Além disso, a cavidade oral pode funcionar como um reservatório para a disseminação futura dessas infecções. Para um controlo adequado deste problema, deve ser prestada uma maior atenção às práticas de sexo oral, à promoção do uso do preservativo e à educação relativamente a práticas sexuais seguras. Por outro lado, o exame da cavidade oral deve ser parte integrante da avaliação de qualquer indivíduo com suspeita de uma infecção sexualmente transmissível. Neste artigo, a transmissão oral de várias infeções virais e bacterianas é revista, nomeadamente a infeção pelo vírus do papiloma humano, herpes genital, sífilis e gonorreia, entre outras.

Palavras-chave: Comportamento Sexual; Doenças da Boca; Doenças Sexualmente Transmissíveis/transmissão

\section{INTRODUCTION}

In consonance with behavioral changes in sexual practices over the last few decades, oral transmission of traditional sexually transmissible infections (STIs) has been increasingly recognized. ${ }^{1}$ This problem becomes even more important if one considers the existence of popular beliefs stating that "oral sex is not sex" and that oral sex is safe in terms of conception risk and transmission of diseases, thus not requiring physical protection such as a condom. ${ }^{2}$ Accordingly, recent studies have confirmed that condom use during oral sex is minimal. ${ }^{2}$

Transmission of STIs can occur during unprotected sexual contact, by the exchange of body fluids during any type of activity. Intact mucous membranes usually prevent infection by pathogenic microrganisms such as those that cause STIs. However, if the mucous membranes of the mouth, vagina, or perianal tissues become torn or ulcerated, transferral of STIs is facilitated. ${ }^{3}$ Additionally, oral ulcers such as those caused by an STI are known to increase the risk of human immunodeficiency virus (HIV) transmission and acquisition. ${ }^{4}$

Patients harboring an STI may first present lesions in the oral cavity, as these may be visible and interfere with basic functions such as speech or swallowing. ${ }^{5}$ However, it is important to note that STIs in the oral cavity are frequently asymptomatic, thus making this place a niche for future spread of these infections. Currently, it is known that oral sex can transmit a variety of viral and bacterial STIs, which include genital herpes, syphilis, gonorrhea, human papillomavirus infection and lymphogranuloma venereum, among others. ${ }^{6,7}$

\section{VIRAL STIs \\ Human papillomavirus infection}

Human papillomavirus infection (HPV) is the most common STI worldwide. Orogenital contact is the primary channel by which HPV is transferred to the oral cavity, ${ }^{3}$ where it can then cause a multitude of oral manifestations including squamous papillomas, oral vulgar warts, condylomata acuminata and squamous cell carcinoma (Figs. 1 and 2). Although sexual transmission through orogenital contact is by far the predominant means of transmission of HPV to the oral mucosa, it is important to note that autoinoculation can also occur (for example, from primary genital lesions). ${ }^{1,5}$ The incidence of HPV infection of mucosal surfaces, including the oral cavity, is increasing, particularly in HIV patients.

1. Serviço de Dermatovenereologia. Hospital de Santa Maria. Centro Hospitalar e Universitário de Lisboa Norte. Lisboa. Portugal.

2. Clínica Universitária de Dermatologia. Faculdade de Medicina da Universidade de Lisboa. Lisboa. Portugal.

3. Instituto de Higiene e Medicina Tropical. Universidade Nova de Lisboa. Portugal.

$\triangle$ Autor correspondente: Catarina Queirós. catarina.squeiros@gmail.com

Recebido: 14 de abril de 2019 - Aceite: 17 de junho de 2019 | Copyright @ Ordem dos Médicos 2019 


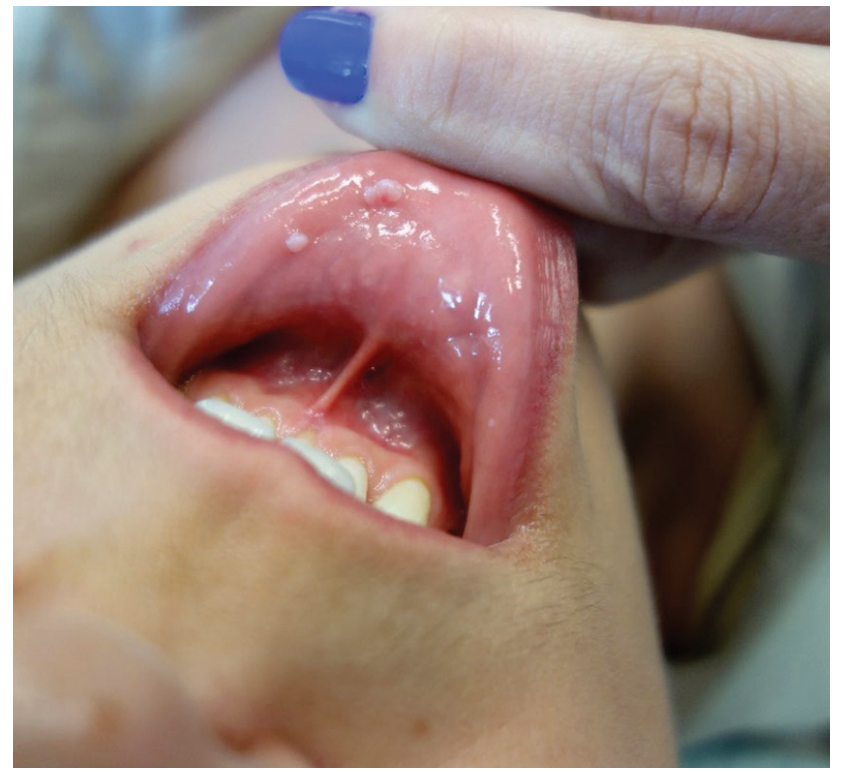

Figure 1 - HPV infection of the oral cavity: two condilomas in the inner lower lip

This appears to occur despite the use of antiretroviral therapy, and is even more problematic as the treatment in this group is particularly challenging. ${ }^{5}$

In general, HPV subtypes found in the oral cavity are 'low risk' subtypes in terms of oncogenic potential. ${ }^{8}$ Squamous papillomas and oral verrucae are generally referred to as common oral warts and may have a sexual route of transmission. Condyloma acuminatum is the most commonly encountered STI and is often caused by low-risk HPV subtypes 6 and 11. It is a benign lesion with a predominant anogenital distribution; however, oral sex practices enable the spread of condilomas to the oral cavity, with reports of lesions on the labial mucosa, soft palate, lingual frenulum, and the tongue. ${ }^{3,5}$

The HPV subtypes $16,18,31$, and 33 are associated with cervical cancer, and are also a risk factor for the development of anal, penile, and oropharyngeal cancers. ${ }^{9}$ HPV-16 is indeed associated with most HPV-associated oropharyngeal squamous cell carcinomas, whose incidence has been increasing in the last two decades. The link between oral sex and oropharyngeal HPV infection is now well established as a strong association between them has been found in previous studies. ${ }^{10}$ Patients with HPVassociated oropharyngeal squamous cell carcinomas usually tend to be white men, younger than 60 years old, with no or little tobacco exposure and with a good performance status. High-risk sexual behaviours, such as multiple sex partners and increased oral sex practices, also seem to be common in this group of patients..$^{5,11,12}$

\section{Herpes simplex virus}

There are two types of herpes simplex virus (HSV), type 1 and type 2, and in both types sexual transmission can occur. After primo-infection, HSV remains latent in the sensory ganglia, where it persists for life. Reactivation may then occur either spontaneously or after certain stimuli,

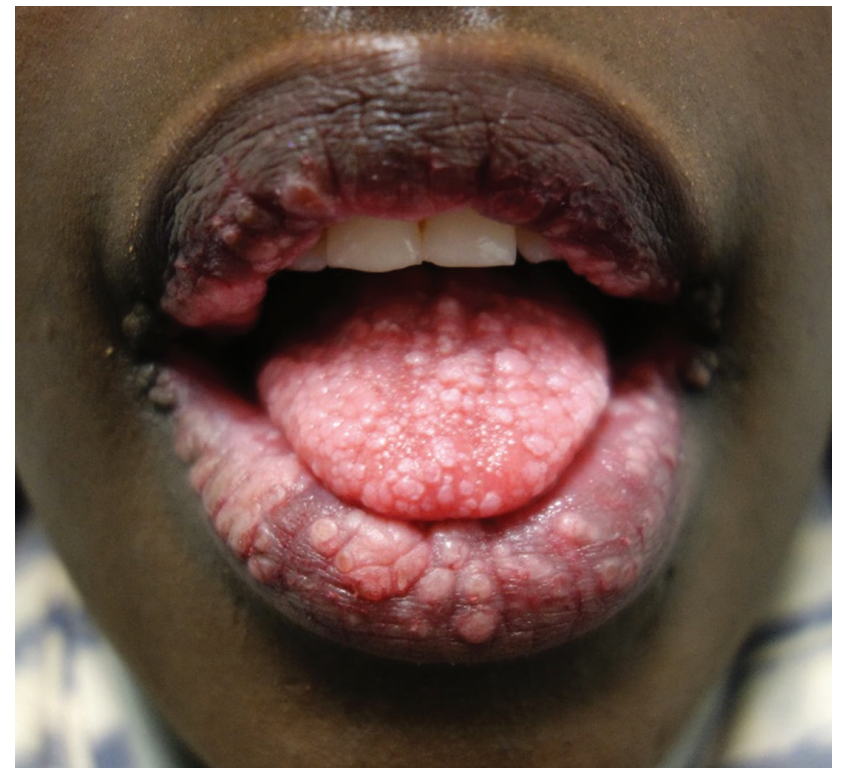

Figure 2 - HPV infection of the oral cavity with multiple condylomata acuminata in an HIV-infected patient

such as stress. While in the latent stage, asymptomatic shedding of HSV may occur, making transmission possible even in patients with no symptoms. ${ }^{13}$

HSV-1 causes recurrent herpes labialis, and on average, less than $50 \%$ genital herpetic infections. ${ }^{3,14}$ Primary infection with this specific agent usually occurrs in childhood by mucocutaneous contact with an infected person, making sexual transmission less common. ${ }^{1,5}$ The clinical picture is tipically presented with fever, sore throat and painful vesicles located in the buccal and gingival mucosa. In most severe cases, gingivostomatitis can be accompanied by dysphagia and lymphadenopathy, and in some cases a serious pharyngitis can occur. On the other side, HSV-2 is the aetiological pathogen associated with most cases of genital herpes. ${ }^{3}$ The main route of HSV-2 transmission is by sexual contact, usually among young adults, producing genital lesions or, less commonly, oral lesions. ${ }^{1}$ Oral herpetic lesions that are caused by HSV-2 are clinically indistinguishable from those caused by HSV-1 (Fig. 3). ${ }^{3}$

\section{Moluscum contagiosum}

Moluscum contagiosum (MC) is caused by a DNA virus of the poxvirus family, which can be transmitted by autoinoculation, intimate physical contact or fomites. In adults, the main route of transmission is by sexual contact, including oral and anal sex, with lesions usually located in the place of inoculation. ${ }^{15}$

$\mathrm{MC}$ lesions in the oral cavity are traditionally shown on the lips and perioral region, and are more frequent in men than in women. ${ }^{1}$ Less frequent locations include the buccal mucosa, palate, or gums. ${ }^{1}$ These lesions commonly present themselves as asymptomatic skin-colored or erythematous papules, posing differential diagnosis with common conditions such as pyogenic granuloma, hemangioma and condylomas. ${ }^{15}$ The lesions tend to occur in clusters, and when extensive, are often markers for advanced HIV disease. ${ }^{5}$ 


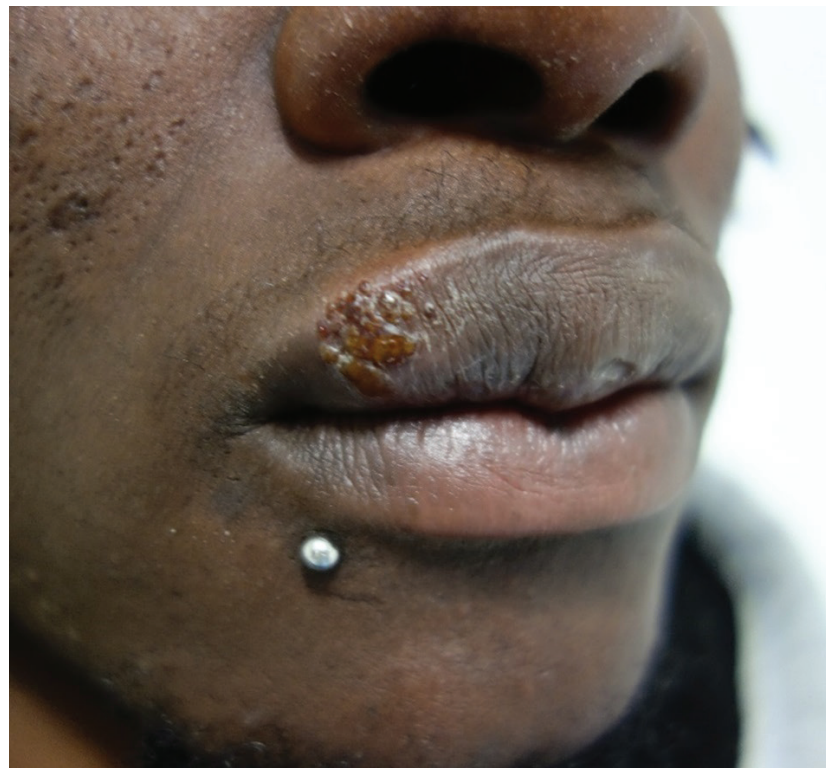

Figure 3 - Herpes simplex infection of the upper lip. In this patient, HSV-2 was identified by polymerase chain reaction

\section{Human immunodeficiency virus}

Human immunodeficiency virus (HIV) is a bloodborne viral pathogen that may be transmitted during unprotected sexual activity, sharing needles during illicit drug use, after receiving HIV-infected organ or tissue transplants, or by exposing mucous membranes or non-intact skin to HIVinfected blood. ${ }^{3}$

Regarding sexual transmission, it is known that the practice of oral sex is less effective in the transmission of HIV than other sexual practices, with the risk of transmission being very low. However, patients should be advised that the possibility of orogenital transmission exists. ${ }^{16}$
Oral manifestations of HIV infection are nonspecific and usually associated with the underlying state of immunossupression, being more common as the CD4 count decreases. ${ }^{17}$ Oropharyngeal infection with HSV, HPV or Candida species, oral hairy leukoplakia, necrotizing ulcerative gingivitis and Kaposi sarcoma are examples. ${ }^{3,17}$

\section{BACTERIAL STIS Syphilis}

Syphilis is transmitted by Treponema pallidum subspecies pallidum and is the prototype of a sexually transmitted disease with oral lesions. ${ }^{1}$ In recent years, after the effective control of the epidemy of Acquired Immunodeficiency Syndrome (AIDS) in the United States and Europe, the incidence of syphilis has been increasing again, mainly due to a change in sexual practices, specifically a decrease in condom usage..$^{18}$ The majority of cases of syphilis now occur in young adults, specially men who have sex with men (MSM). ${ }^{19}$

Primary syphilis is characterized by the appearance of a chancre, which originates at the site of penetration of the organisms into the mucosa. The chancre is usually a painless and indurated ulcer with raised borders, which lasts between 3 and 6 weeks and is highly contagious. Chancres are more frequent in the anogenital area; however, extragenital locations have been reported in $12 \%$ to $14 \%$ of cases. ${ }^{19}$ From these, an estimated $40 \%$ to $75 \%$ occur in the mouth (Fig. 4), ${ }^{3}$ with the oral mucosa being the most frequent site for extragenital primary syphilis. Oral lesions in this setting are highly infectious, with a reported transmission rate of $18 \%$ to $80 \%$ during sexual contact. ${ }^{19}$ Besides mucosal lesions, these patients often present also with associated ipsilateral adenopathies. ${ }^{18}$
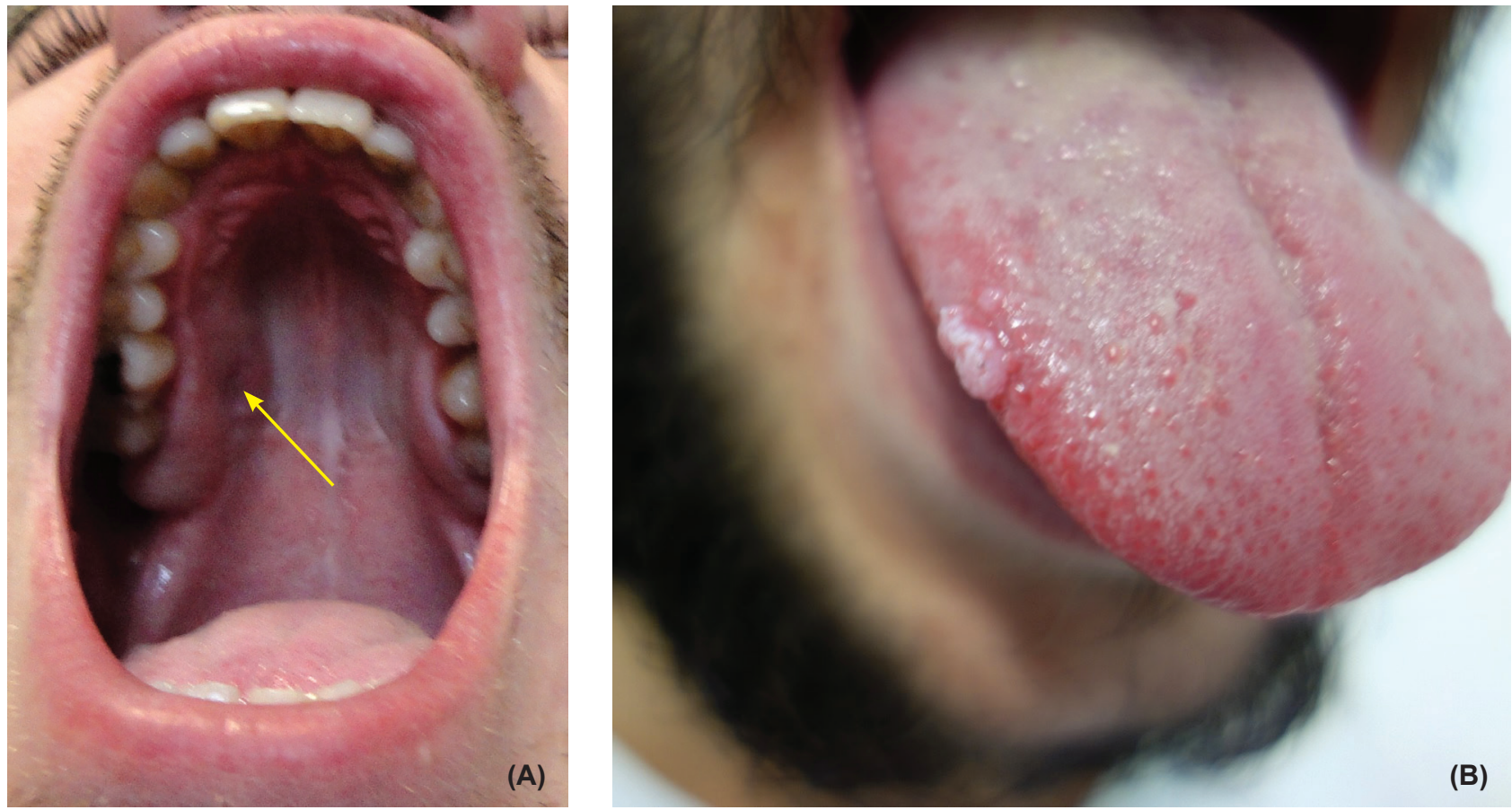

Figure 4 - Syphilis in the oral cavity: (A) primary chancre in the palate; $(B)$ condylomata lata on the side of the tongue 
Secondary syphilis can also give rise to oral and pharyngeal manifestations, estimated to occur in approximately $30 \%$ of patients at this stage. In secondary syphilis, oral manifestations are polymorphous, the most common being condyloma lata. These are raised, fleshy, white to grey lesions, often developing within the vicinity of the primary chancre (preferentially located on the lips, tongue, buccal mucosa and palate). Other manifestations of secondary syphilis include lymphadenopathy, a maculopapular rash and alopecia, among others. ${ }^{3}$

Tertiary syphilis is rare and the characteristic lesion is the gumma, which in the oral cavity may affect the palate, tongue or tonsils. ${ }^{18}$ The gumma is a long-standing granulomatous lesion with a necrotic central core, which can range in size from a few millimeters to large masses with more than $1 \mathrm{~cm}$ in diameter. ${ }^{3}$ Oral gummata are not common, but when they do occur, they can have significant consequences, as the necrotic core of palatal gummata can be expansive and perforate the nasal cavity or the maxillary sinus. It is important to note that oral manifestations of secondary and tertiary syphilis are not a direct consequence of the practice of oral sex. ${ }^{1}$

\section{Chlamidia trachomatis}

Urogenital infection with Chlamydia trachomatis is the most prevalent bacterial STI in developed countries. ${ }^{20}$ Although treatment is straightforward, STI screening programmes have been unable to stop the ongoing epidemics of $C$. trachomatis. There are no specific oral manifestations of chlamydial infections. Patients may complain of a sore throat or have a generalized inflammation of the pharynx and/or tonsils. ${ }^{3}$ However, pharyngeal C. trachomatis infection is usually asymptomatic and lesions can rarely be seen in the pharynx. ${ }^{21}$ In these cases, C. trachomatis in the oroparynx can be identified by molecular biology techniques.

Some countries recommend screening for pharyngeal C. trachomatis under certain circumstances, but this is not a common practice worldwide, ${ }^{20}$ as pharyngeal chlamydia is much less common compared to pharyngeal gonorrhoea. ${ }^{22}$ However, a study from van Rooijen MS et al revealed that $53 \%$ of MSM and $32 \%$ of female patients with pharyngeal $C$. trachomatis did not have a concurrent anogenital $C$. trachomatis infection, highlighting the risk of missing cases if screening is only performed in the anogenital area. ${ }^{20}$

Chlamydia infection of the genital tract is a well recognized cause of infertility, with recent studies proposing that oral sex can also be associated with this undesired consequence. The hypothesis is that infectious chlamydiae transmitted via oral sex colonize the gastrointestinal tract, thereby persisting undetected by the human host and tolerated by the immune system for extended periods of time, potentially leading to pelvic inflammatory disease and other serious complications. ${ }^{23}$

Lymphogranuloma venereum is a sexually transmited systemic infection caused by C. trachomatis serovars L1-L3. Its incidence has increased in the last decade in Western countries, especially among MSM. ${ }^{24}$ Lymphogranuloma venereum is a common cause of proctitis, but cases of infections in other locations (e.g. urethral and pharyngeal) have been published. ${ }^{25,26}$ The discrepance between the rates of rectal and oral mucosa infection seem to be explained by tissue tropism, as these bacteria show a higher affinity for rectal mucosa than for orapharyngeal mucosa. ${ }^{27}$

Oral infection may result in clinical or subclinical pharyngitis, and the organisms may pass through the gastrointestinal tract to the large intestine and rectum. ${ }^{25}$ Pharyngeal infection by these serovars of Chlamydia can be characterized by nonspecific symptoms such as cervical adenopathies, odynophagia or tongue ulcers; however, the vast majority of cases are subclinical or asymptomatic. ${ }^{26}$ Therefore, the presence of a pharyngeal venereal lymphogranuloma can act as a reservoir for infection. ${ }^{20,24,26}$ Prospective studies are required to evaluate whether routine screening of nonrectal lymphogranuloma venereum in MSM is needed and cost-effective.

\section{Neisseria gonorrheae}

Gonorrhoea is a STI caused by the bacteria Neisseria gonorrhoeae. It is associated with urethritis and proctitis in men, with ectopic pregnancy and tubal infertility in women, and increases the susceptibility and transmissibility of HIV in both sexes. ${ }^{28}$

The susceptibility for $N$. gonorrhoeae infection varies depending on the charactheristics of the tissues; for example, the columnar epithelium of the cervix and urethra and the transitional epithelium of the oropharynx and rectum are common entry points for gonococcal infection, whereas the stratified squamous epithelium that composes the skin and the mucosal lining of the oral cavity appears more resistant to $N$. gonorrhoeae. ${ }^{3}$

Oropharyngeal colonization by $N$. gonorrheae was first described in 1944 and, since then, a lot of studies have been conducted around this subject. ${ }^{29}$ Although less common than genital colonization, ${ }^{29}$ oropharyngeal infection with $N$. gonorrheae can present itself through a variety of manifestations such as pharyngitis, tonsillitis, gingivitis, stomatitis or glossitis. ${ }^{30}$ However, it is important to note that most cases of pharyngeal gonococcal infection are asymptomatic, with only $15 \%$ of individuals demonstrating symptoms such as sore throat and cervical adenopathies.

In asymptomatic individuals, the best way of identifying $N$. gonorrhoeae in the oropharynx is by molecular biology techniques. ${ }^{30}$

When symptomatic, gonococcal infection of the oral cavity usually results in an acute ulcerative inflammation, which is intensely painfull; these multiple ulcers are accompanied by a bright red oral mucosa that bleeds easily and by nonadherent pseudomembranes, which may be white, yellow, or grey in color. ${ }^{14}$ These lesions are not specific, posing a broad differential diagnosis, such as with herpes simplex virus infection, erythema multiforme or immunobullous disorders. ${ }^{1,5}$

Recent studies confirmed a significant prevalence of extragenital $N$. gonorrhoeae infections, particularly among 
MSM. As gonococcal infections at the anorectal or oropharyngeal regions are frequently asymptomatic, and often occur without concurrent urogenital infection, they may be undiagnosed, thereby increasing the risk of complications and constituting potential disease reservoirs. ${ }^{4}$ To address this public health concern, the need for screening and testing for $N$. gonorrhoeae at extragenital sites has been emphasised in recent years, ${ }^{22}$ and several guidelines have been made accordingly. The Centers for Disease Control and Prevention $(C D C)^{31}$ and the International Union against Sexually Transmitted Infections (IUSTI) ${ }^{32}$ generally recommend screening for anorectal and/or oropharyngeal gonorrhoea in MSM according to the reported history of anal and/ or oral sexual exposure; on the other hand, other groups recommend annual screening for MSM (or every $3-6$ months for high-risk MSM) at all sites, regardless of the history of sexual contact. ${ }^{4}$

Gonococcal infection at extragenital sites is also thought to facilitate transmission and/or acquisition of HIV, not only because of shared behavioural risk factors for both STIs (including inadequate condom use and multiple sexual partners), but also due to an increased biological susceptibility related to inflammation and immunosuppression. ${ }^{4}$

Most gonococcal and chlamydial infections in MSM occur in extra-genital sites, such as the oropharynx and/ or the rectum. These infections are usually asymptomatic and underdiagnosed due to inadequate screening. As such, gonorrhoea and chlamydia of the oropharynx may play an important role in sustaining the extremely high rates of bacterial STI observed in this population. ${ }^{33}$ In the case of Neisseria gonorrhoeae, it is estimated that a quarter to a third of all cases of symptomatic gonococcal urethritis among MSM can be attributed to oral sex. ${ }^{33}$ This observation strongly supports the idea that the failure to identify and eradicate $N$. gonorrhoeae from the oropharynx plays a critical role in sustaining the extremely high rates of gonorrhoea observed in MSM, and that efforts to promote widespread pharyngeal screening for gonorrhoea among MSM should be advised. ${ }^{33}$

On the other hand, the oropharyngeal niche provides an ideal environment for generating antimicrobial resistance through horizontal transfer of genetic material from commensal Neisseria and other bacterial species to N. gonorrhoeae. ${ }^{34}$ This fact, combined with the intrinsic inability of antimicrobial agents to achieve high extracellular concentrations in tonsillar and other oropharyngeal tissues, makes the oropharynx the anatomical site where treatment has a lower efficacy. ${ }^{34}$ Therefore, future evaluations of new drugs or novel drug combinations for gonorrhoea should assess cure in the oropharynx. ${ }^{34}$

Prevalence of gonorrhoea can be reduced by increasing condom usage during oral and anal sex. ${ }^{28}$ However, this may be difficult particularly for oral sex, as it is usually perceived to be safe by patients. Healthcare professionals are therefore essential in promoting condom use and safe sexual practices. Additionally, as pharyngeal N. gonorrhoeae infections may be asymptomatic, appropriate routine screening and early treatment should be considered in high-risk populations. ${ }^{2}$

\section{CONCLUSION}

Changes in sexual habits and pratices inevitably lead to a change in clinical appearance of STIs. The mucous membranes of the oral cavity are vulnerable to direct inoculation of many of these infections, with the practice of oral sex significantly contributing to many cases of syphilis and gonorrhea. In order to successfully control these infections, programmes will need to use strategies such as frequent testing of the oropharynx reservoir, in addition to the promotion of condom use. Moreover, it is important for the attending physician to be aware of these manifestations so as to make an early diagnosis and initiate adequate treatment. Programs for the prevention of sexually transmitted diseases should include greater attention to oral sex, including education on safe oral sex practices and awareness of the oral symptoms of sexually transmitted diseases. The examination of the oral cavity should be an integral part of the evaluation of any patient suspected of harboring an STI.

\section{PROTECTION OF HUMANS AND ANIMALS}

The authors declare that the procedures were followed according to the regulations established by the Clinical Research and Ethics Committee and to the Helsinki Declaration of the World Medical Association.

\section{DATA CONFIDENTIALITY}

The authors declare having followed the protocols in use at their working center regarding patients' data publication.

\section{CONFLICTS OF INTEREST}

All authors report no conflict of interest.

\section{FUNDING SOURCES}

This research received no specific grant from any funding agency in the public, commercial, or not-for-profit sectors.

study in a STI clinic in Lisbon, Portugal. Acta Med Port. 2018;31:247-53.

5. Bruce AJ, Rogers RS. Oral manifestations of sexually transmitted diseases. Clin Dermatol. 2004;22:520-7.

6. Edwards S, Game C, Edwards S, Came C. Oral sex and the transmission of non-viral STIs. Sex Transm Infect. 1998;74:95-100.

7. Edwards S, Carne C. Oral sex and the transmission of viral STIs. Sex Transm Infect. 1998;74:6-10.

8. Summersgill KF, Smith EM, Levy BT, Allen JM, Haugen TH, Turek LP. Human papillomavirus in the oral cavities of children and adolescents. 
Oral Surg Oral Med Oral Pathol Oral Radiol Endod. 2001;91:62-9.

9. Nakashima K, Shigehara K, Kawaguchi S, Wakatsuki A, Kobori $Y$, Nakashima K, et al. Prevalence of human papillomavirus infection in the oropharynx and urine among sexually active men: a comparative study of infection by papillomavirus and other organisms, including Neisseria gonorrhoeae, Chlamydia trachomatis, Mycoplasma spp., and Ureapl. BMC Infectious Dis. 2014;14:43.

10. Gillison ML, Pawlita M, Kreimer AR, D'Souza G, Westra WH, Fakhry C, et al. Case-control study of human papillomavirus and oropharyngeal cancer. N Engl J Med. 2007;356:1944-56.

11. Tanaka TI, Alawi F. Human papillomavirus and oropharyngeal cancer. Dental Clin N Am. 2018;62:111-20.

12. Ang K, Harris J, Wheeler R, Weber R, Rosenthal DI, Nguyen-Tân PF, et al. Human papillomavirus and survival of patients with oropharyngeal cancer. N Engl J Med. 2010;363:24-35.

13. Preston CM, Efstathiou S. Molecular basis of HSV latency and reactivation. In: Human herpesviruses: biology, therapy, and immunoprophylaxis. Cambridge: Cambridge University Press; 2007.

14. Chue PW. Gonorrhea - its natural history, oral manifestations, diagnosis, treatment, and prevention. J Am Dental Assoc. 1975;90:1297-301.

15. Fornatora ML, Reich RF, Gray RG, Freedman PD. Intraoral molluscum contagiosum: a report of a case and a review of the literature. Oral Surg Oral Med Oral Pathol Oral Radiol Endod. 2001;92:318-20.

16. Robinson E, Evans B. Oral sex and HIV transmission. AIDS. 1999;13:737-8.

17. Glick M, Muzyka BC, Lurie D, Salkin LM. Oral manifestations associated with HIV-related disease as markers for immune suppression and AIDS. Oral Surgery Oral Medicine Oral Pathol. 1994;77:344-9.

18. Viñals-Iglesias $H$, Chimenos-Küstner $E$. The reappearance of a forgotten disease in the oral cavity: syphilis. Med Oral Patol Oral Cir Bucal. 2009;14:416-20.

19.Yu X, Zheng H. Syphilitic chancre of the lips transmitted by kissing Medicine. 2016;95:1-2.

20. Van Rooijen MS, Van Der Loeff MF, Morré SA, Van Dam AP, Speksnijder AG, De Vries HJ. Spontaneous pharyngeal Chlamydia trachomatis RNA clearance. A cross-sectional study followed by a cohort study of untreated STI clinic patients in Amsterdam, the Netherlands. Sex Transm Infect. 2015;91:157-64.

21. Hamasuna R, Hoshina S, Imai H, Jensen JS, Osada Y. Usefulness of oral wash specimens for detecting Chlamydia trachomatis from high-risk groups in Japan. Int J Urol. 2007;14:473-5.
22. Forcey DS, Bradshaw CS, Read TR, Hocking JS, Chen MY, Fairley CK, et al. Contribution of sexual practices (other than anal sex) to bacterial sexually transmitted infection transmission in men who have sex with men: a cross-sectional analysis using electronic health records. Sex Transm Infect. 2013;90:55-7.

23. Bavoil PM, Marques PX, Brotman R, Ravel J. Does active oral sex contribute to female infertility? J Infect Dis. 2017;216:932-5.

24. Ossewaarde JM, den Hollander JC, Thio HB, Thomeer MG, Neumann $\mathrm{MH}$, Nieuwenhuis RF, et al. Resurgence of lymphogranuloma venereum in western Europe: an outbreak of Chlamydia trachomatis serovar L2 proctitis in The Netherlands among men who have sex with men. Clin Infect Dis. 2004;39:996-1003.

25. de Vries HJ. The enigma of lymphogranuloma venereum spread in men who have sex with men. Sex Transm Dis. 2016;43:420-2.

26. Dosekun O, Edmonds S, Stockwell S, French $P$, White J. Lymphogranuloma venereum detected from the pharynx in four London men who have sex with men. Int J STD AIDS. 2013;24:495-6.

27. Riera-Monroig J, Fuertes de Vega I. Lymphogranuloma venereum presenting as an ulcer on the tongue. Sex Transm Infect. 2019;95:169-70.

28. Hui B, Fairley CK, Chen M, Grulich A, Hocking J, Prestage G, et al. Oral and anal sex are key to sustaining gonorrhoea at endemic levels in MSM populations: a mathematical model. Sex Transm Infect. 2015;91:365-9.

29. Osborne NG, Grubin L. Colonization of the pharynx with Neisseria gonorrhoeae: experience in a clinic for sexually transmitted diseases. Sex Transm Dis. 1979:6:253-6.

30. Wiesner P, Tronca E, Bonin P, Pedersen A, Holmes K. Clinical spectrum of pharyngeal gonococcal infection. N Engl J Med. 1973;288:181-5.

31. Workowski KA, Bolan GA; Centers for Disease Control and Prevention. Sexually Transmitted Diseases Treatment Guidelines, 2015. MMWR 2015;64:1-137.

32. Bignell C, Unemo M. 2012 European guideline on the diagnosis and treatment of gonorrhoea in adults. Int J STD AIDS. 2012;24:85-92.

33. Barbee L, Khosropour C, Dombrowski J, Manhart L, Golden M. An estimate of the proportion of symptomatic gonococcal, chlamydial and non-gonococcal non-chlamydial urethritis attributable to oral sex among men who have sex with men: a case-control study. Sex Transm Infect. 2016;92:155-60.

34. Lewis DA. Will targeting oropharyngeal gonorrhoea delay the further emergence of drug-resistant Neisseria gonorrhoeae strains? Sex Transm Infect. 2015;91:234-7. 